\title{
Analysis of the influence of different soil properties on the strength characteristics of cement soil
}

\author{
Hewen $\mathrm{Liu}^{1,2,3^{*}}$, and Wenjia $\mathrm{Wu}^{1,2}$ \\ ${ }^{1}$ CCCC First Harbor Eng. Co., Ltd. \\ ${ }^{2}$ Tianjin Port Engineering Institute Co., Ltd. of CCCC First Harbor Eng. Co., Ltd. \\ ${ }^{3}$ Key Laboratory of Port Geotechnical Engineering of the Ministry of Communication Tianjin, China
}

\begin{abstract}
When deep cement mixing method (DCM) uses cement as solidified material to treat marine soft foundation, the strength of soil is different due to the diversity of water content, void ratio and particle fineness. Based on the Pearl River Estuary DCM project, this paper uses a variety of PO.42.5 cement and marine soft soil in the Pearl River estuary area to carry out indoor mix proportion tests. There are four kinds of soil: flowing mud, silt, muddy soil and silt. The test results show that the strength of cement soil in different soil layers is diversity. The effect of cement solidification treatment on silt and muddy soil is good, followed by silt, and flowing mud is slightly poor. The selected PO.42.5 cement can meet the strength requirements of DCM.
\end{abstract}

\section{Introduction}

Underwater deep cement mixing method (DCM) is an advanced marine soft soil treatment technology introduced in China in recent years. It uses cement as solidification material to react with marine soft soil to form cement soil with certain strength. It has the advantages of high construction efficiency, high bearing capacity and small settlement deformation. Generally, due to different depositional ages, soil thickness and soil properties in different areas are different. Before construction, in order to ensure the DCM treatment effect, the indoor mix proportion test of cement soil should be carried out first; Liu Zhijun ${ }^{[3]}$ and others conducted a detailed study on the indoor sample preparation method of cement soil from the aspects of model selection, mix proportion mixing, vibration and maintenance; Chen Zhongxue et al. ${ }^{[4-6]}$ The development law of unconfined compressive strength of cement soil is discussed from the aspects of cement grade, different cement content, different age and different soft soil conditions; He Yingxi ${ }^{[7]}$ and others have carried out the indoor proportioning test of cement reinforcement for soft soil in Hong Kong and the treatment effect of in-situ deep cement mixing pile test.

Generally, cement grade is the main basis for selecting cement, which is the index reflecting the strength of cement; cement grade is usually determined by mixing one part of cement, three parts of China ISO standard sand and 0.5 water cement ratio according to the method specified in test method for strength of cement mortar (ISO method) (GB/T 17671-1999) to form plastic mortar, which is made into $40 \mathrm{~mm} \times 40 \mathrm{~mm} \times 160 \mathrm{~mm}$, the standard specimen of $40 \mathrm{~mm} \times 160 \mathrm{~mm}$ is cured under standard conditions. When it reaches the age of $3 \mathrm{D}, 7 \mathrm{~d}$ and $28 \mathrm{~d}$, the flexural strength and compressive strength are measured, and the average compressive strength of $28 \mathrm{~d}$ is taken to determine the cement grade. The cement label determined by the above gel method mainly depends on the hydration reaction between cement and standard sand. When the reaction of cement and marine soft soil is different, the calcination process, mineral composition, particle fineness and hardening reaction temperature of cement from different manufacturers are different, and the organic matter content, erosive ion, $\mathrm{pH}$ value and mechanical properties of different soil properties are different. ${ }^{[8]}$ The results show that the strength of cement soil formed by the same grade cement is different; therefore, according to the indoor mix proportion test results of the actual soil layer in the construction area, scientific and reasonable selection of cement manufacturers will help to improve the treatment effect and save the economic cost; this paper aims at the Pearl River Estuary DCM treatment project, through the indoor mix proportion test of three brands of cement, analyzes and studies the strength of different soil cement soil law.

\section{Indoor mix proportion test method}

\subsection{Test process}

According to the experience of cement mixing soil mix proportion test for many years, the test is carried out according to the following process. In order to ensure the comparability of the test results, the soil and water used in the test are taken from the site, and the soil samples

${ }^{*}$ Corresponding author's e-mail: liuhewen@tpei.com.cn 
are sealed after being taken out from the site, ignoring the moisture change during the transportation process; generally, the flowing mud is not easy to obtain, and it is made by adding water to the surface mud during the test. In order to simulate the site construction situation, cement and water are mixed in advance to make cement slurry and then mixed with soil. The sample preparation, molding, formwork removal, curing and unconfined compressive strength test shall strictly comply with the requirements of "code for design of cement soil mix proportion" (JGJ/T 233-2011).

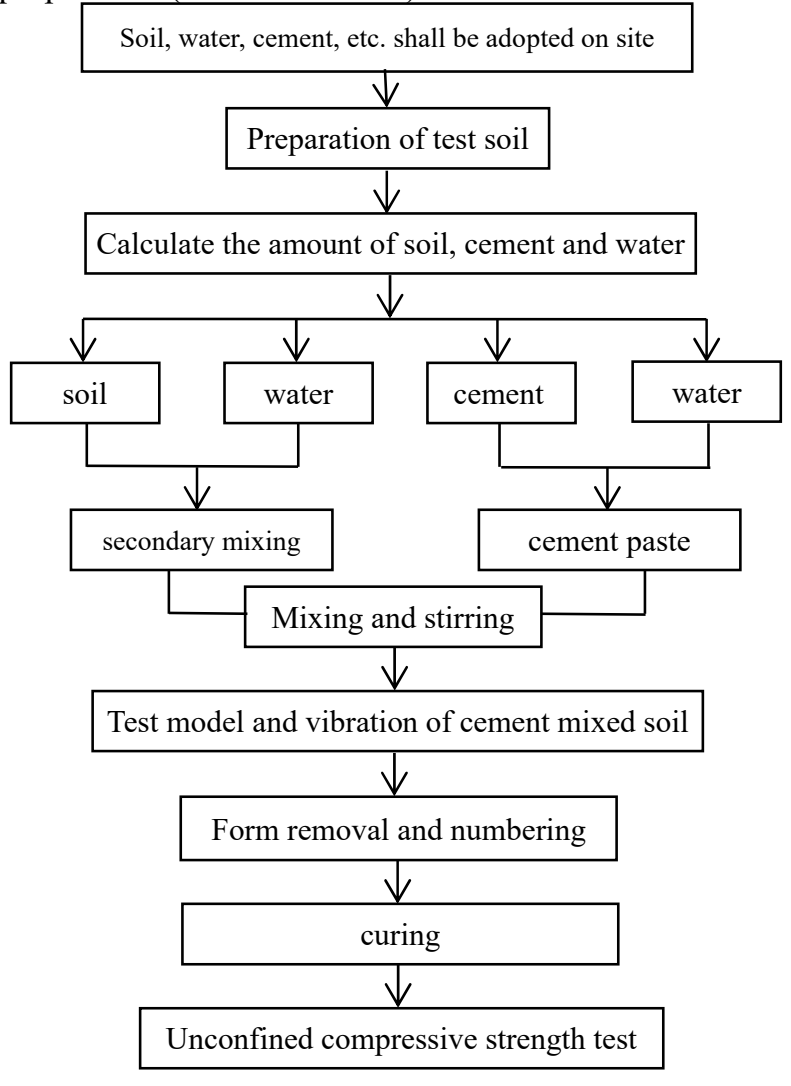

Fig.1. Flow chart of soil-cement mix test.

\subsection{Sample preparation}

The sample preparation method is wet soil sample preparation method. After removing the plant rhizome, shell and other debris, stir evenly, calculate and weigh the required wet soil, cement and water according to the preliminary mix proportion parameters. Pour the wet soil into the planetary mixer for mixing, add the cement slurry to continue mixing, set the rotating speed of the mixer to $300 \mathrm{r} / \mathrm{min}$, and the mixing time is about $15 \mathrm{~min}$.

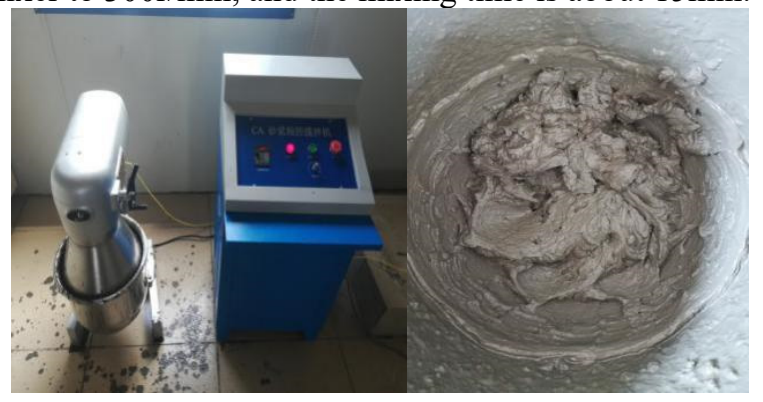

Fig.2. Cement sample mixer and mixed cement soil.

\subsection{Forming}

The $70.7 \mathrm{~mm} \times 70.7 \mathrm{~mm} \times 70.7 \mathrm{~mm}$ cube test mold is used for molding, and a layer of Vaseline is evenly coated on the inner wall of the test mold before use; after the cement soil is evenly mixed, the cube test mold is put into four layers respectively, and each layer is vibrated and compacted on the shaking table after the mold is installed, with each vibration time of $40 \mathrm{~s}$; finally, the surface is scraped and the standard maintenance is carried out after numbering.

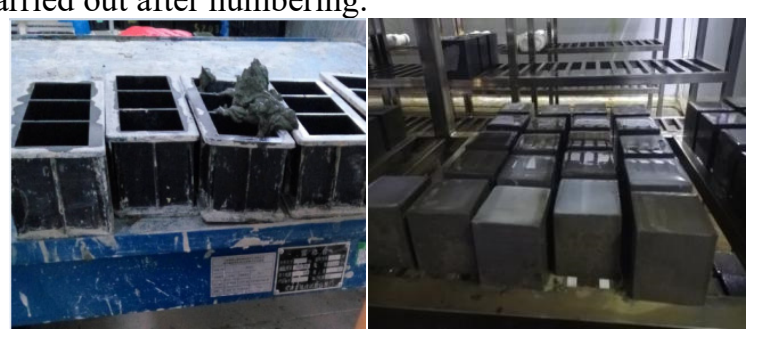

Fig.3. Vibration molding and curing of soil-cement.

\subsection{Demoulding and maintenance}

After 24 hours of molding, demoulding is carried out after the cement soil has a certain strength. Generally, demoulding can be carried out by reversing the test mold, otherwise it can be carried out with the help of pressure pump; the demoulded test block is put into the curing room for curing, the temperature is $(20 \pm 2){ }^{\circ} \mathrm{C}$, and the humidity is more than $95 \%$. After reaching the corresponding test age, the samples were taken out for test.

\subsection{Unconfined compressive strength test}

During the test, the unconfined compressive strength test is carried out at the rate of $0.15 \mathrm{~mm} / \mathrm{min}$ with the side as the compression surface until the sample is damaged. The compression failure curve and fracture surface morphology of the sample are recorded. If necessary, some cement soil is selected for moisture content test.

There are many details in the cement soil mix proportion test. In order to reduce the influence of human factors on the test results, each operation step is quantified reasonably in the test process.

\section{Indoor mix proportion test}

According to the preliminary mix proportion design, PO.42.5 cement is selected as the curing material. This time, three brands of PO.42.5 cement, namely conch, Sinoma and China Resources, are selected for the mix proportion test of cement soil.

\subsection{Soil properties and test parameters}

According to the distribution characteristics of marine soft soil layer in this area, the test soil is composed of flowing mud, silt, muddy soil and silt. The water cement ratio is 0.9 , and the cement content is $240 \mathrm{~kg} / \mathrm{m}^{3} \sim 440$ 
$\mathrm{kg} / \mathrm{m}^{3}$. A total of $14 \mathrm{~d}$ and $28 \mathrm{~d}$ strength tests are conducted. The average values of basic physical parameters of various test soils are shown in Table 1 .

\subsection{Test results}

The indoor mix proportion test of three brands of convective mud and silt at $14 \mathrm{~d}$ and $28 \mathrm{~d}$ ages is carried out, and the test results are shown in Table 2 and Figure 4.

The test results show that: under the current cement content, the $28 \mathrm{~d}$ strength of flowing mud cement soil is between $0.7 \mathrm{MPa} \sim 2.3 \mathrm{MPa}$, and the $28 \mathrm{~d}$ strength of silt cement soil is between $1.15 \mathrm{MPa} \sim 3.05 \mathrm{MPa}$ When the cement content is higher than $400 \mathrm{~kg} / \mathrm{m}^{3}$, the increase of cement content has a significant effect on the strength growth of the flow mud and silt.

Table 1. Basic physical parameters of test soil and cement content.

\begin{tabular}{ccccccc}
\hline $\begin{array}{c}\text { Types of soil } \\
\text { samples }\end{array}$ & $\begin{array}{c}\text { Wet density } \\
\left(\mathrm{g} / \mathrm{cm}^{3}\right)\end{array}$ & proportion & Void ratio & $\begin{array}{c}\text { Moisture content } \\
(\%)\end{array}$ & $\begin{array}{c}\text { Plasticity } \\
\text { index }\end{array}$ & $\begin{array}{c}\text { Liquidity index } \\
\left(\mathrm{kg} / \mathrm{m}^{3}\right)\end{array}$ \\
\hline Flowing mud & 1.47 & 2.76 & 2.66 & 95 & 25 & 2.7 \\
silt & 1.61 & 2.76 & 1.83 & 65 & 23 & 1.65 \\
mucky soil & 1.83 & 2.72 & 1.05 & 38.4 & 11.85 & $240 、 280320 、$ \\
Silt & 1.96 & 2.70 & 0.75 & 27.8 & 8 & 1.83 \\
\hline
\end{tabular}

Table 2. Test data of mixture ratio of flowing mud and silt.

\begin{tabular}{cccccccc}
\hline \multirow{2}{*}{$\begin{array}{c}\text { Types of soil } \\
\text { samples }\end{array}$} & Cement content & \multicolumn{2}{c}{ Conch } & \multicolumn{2}{c}{ China Resources } & \multicolumn{2}{c}{ Sinoma } \\
\cline { 2 - 8 } & $\mathrm{kg} / \mathrm{m}^{3}$ & $14 \mathrm{~d}$ & $28 \mathrm{~d}$ & $14 \mathrm{~d}$ & $28 \mathrm{~d}$ & $14 \mathrm{~d}$ & $28 \mathrm{~d}$ \\
\hline \multirow{3}{*}{ Flowing mud } & 240 & 0.86 & 1.04 & 0.55 & 0.70 & 0.84 & 0.96 \\
& 280 & 1.08 & 1.23 & 0.64 & 0.76 & 0.94 & 1.09 \\
& 320 & 1.18 & 1.47 & 0.81 & 1.05 & 1.06 & 1.15 \\
& 360 & 1.33 & 1.54 & 1.02 & 1.36 & 1.24 & 1.52 \\
& 400 & 1.77 & 2.00 & 1.25 & 1.47 & 1.54 & 1.68 \\
& 440 & 1.97 & 2.30 & 1.84 & 1.96 & 1.85 & 2.05 \\
\hline \multirow{3}{*}{ silt } & 240 & 1.15 & 1.23 & 1.02 & 1.15 & 1.11 & 1.29 \\
& 280 & 1.23 & 1.36 & 1.28 & 1.33 & 1.29 & 1.49 \\
& 320 & 1.39 & 1.63 & 1.40 & 1.50 & 1.48 & 1.63 \\
& 360 & 1.70 & 1.99 & 1.50 & 1.70 & 1.56 & 1.84 \\
& 400 & 1.95 & 2.32 & 1.65 & 2.00 & 1.76 & 1.99 \\
& 440 & 2.72 & 3.05 & 2.31 & 2.50 & 2.02 & 2.54 \\
\hline
\end{tabular}

Table 3. Test data of silty soil and silt mixture.

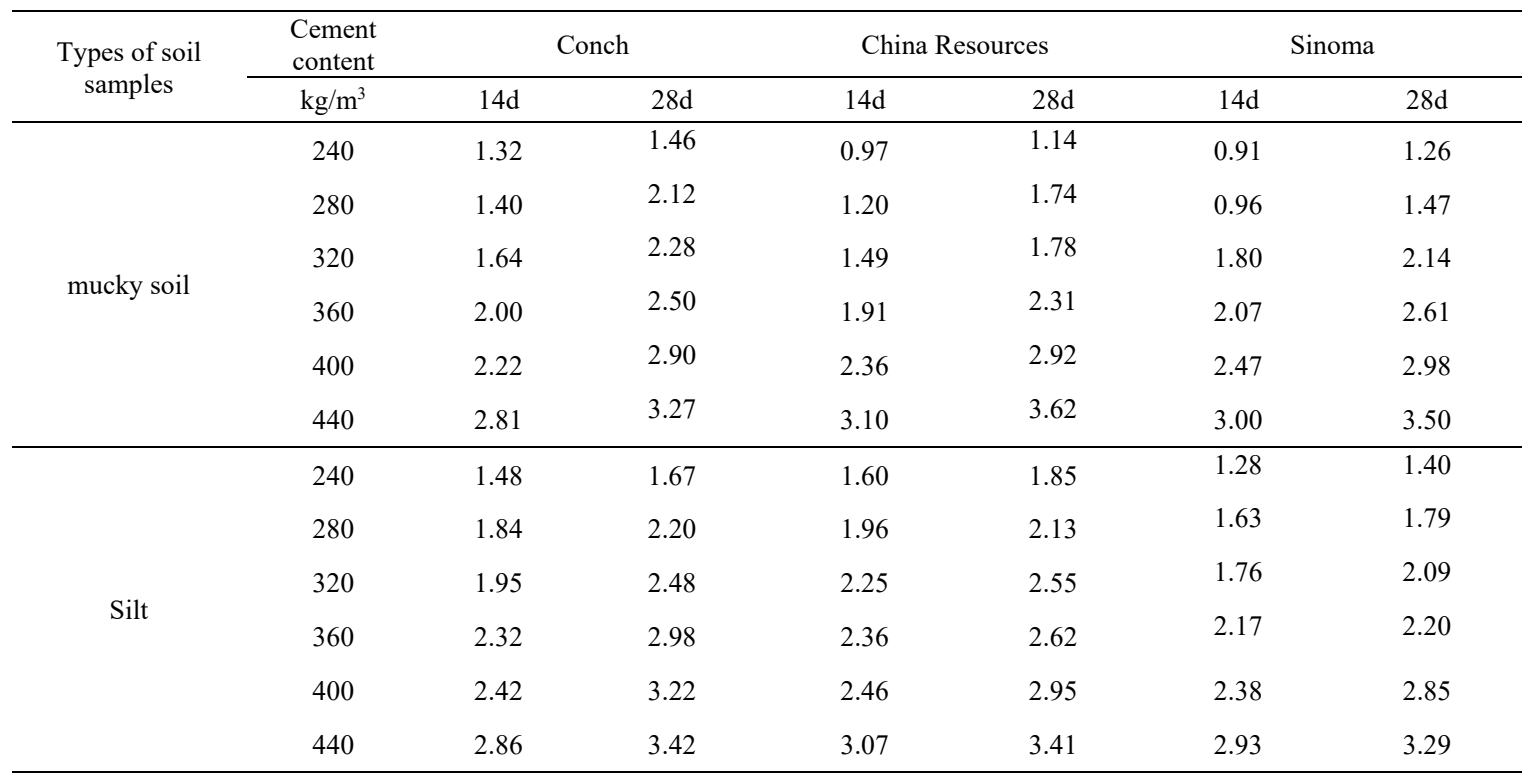


The results show that the strength of cement soil of different brands is different under different cement dosage of flowing mud; the strength of conch cement is close to that of Sinoma cement; when the cement dosage is $400 \mathrm{~kg} / \mathrm{m}^{3}$, the maximum strength deviation is $0.23 \mathrm{MPa}$, which is about $14 \%$ of the cement strength; the strength growth rate of flowing mud at $14 \mathrm{~d}$ and $28 \mathrm{~d}$ age is close, that of China Resources cement is $22.4 \%$, conch cement is $17 \%$, and Sinoma cement is $13.5 \%$; for sludge, three kinds of cement are used When the cement content of brand cement soil is below $360 \mathrm{~kg} / \mathrm{m}^{3}$, the strength characteristics of cement soil are consistent. When the cement content of brand cement soil is above $360 \mathrm{~kg} / \mathrm{m}^{3}$, the strength growth rate from $14 \mathrm{~d}$ to $28 \mathrm{~d}$ is between $11 \% \sim 16 \%$.

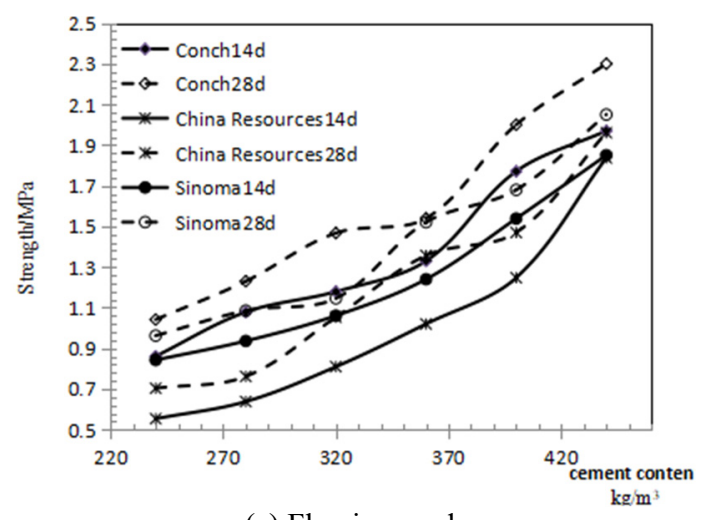

(a) Flowing mud

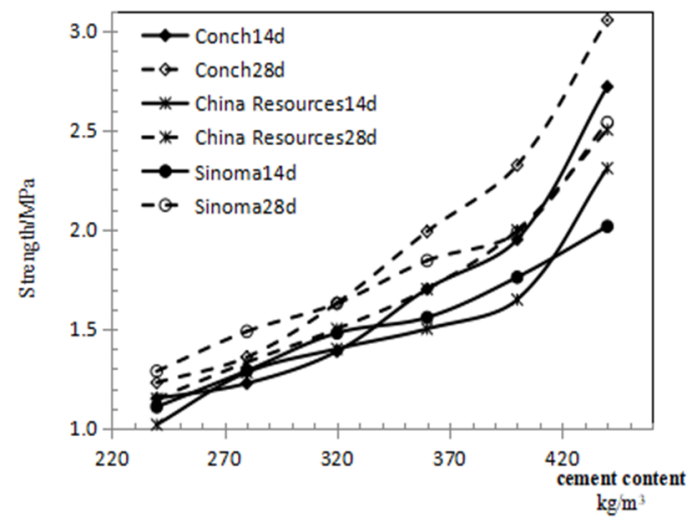

(b) Silt

Fig. 4. Relationship curves between soil-cement strength and cement content of the three brands.

The indoor mix proportion tests of muddy soil and silt with three brands are carried out at the age of $14 \mathrm{~d}$ and 28d. The test results are shown in Table 3 and Figure 5.

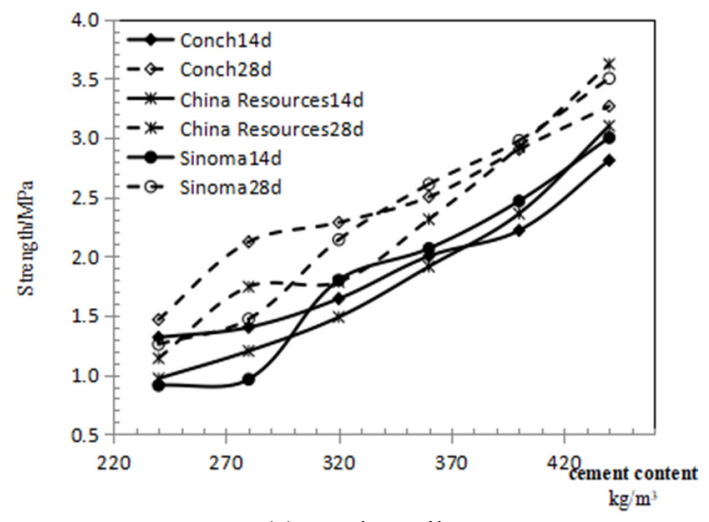

(a) mucky soil

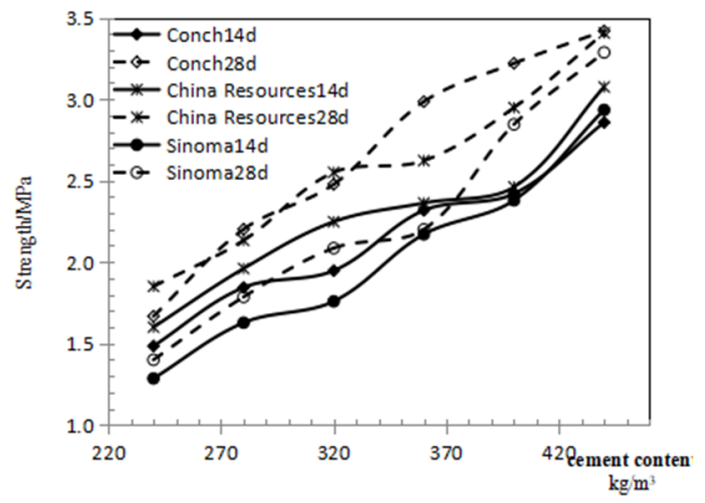

(b) Silt

Fig. 5. Relationship curves between soil-cement strength and cement content of the three brands.

The results show that the $28 \mathrm{~d}$ strength of muddy soil cement is $1.14 \mathrm{MPa} 3.62 \mathrm{MPa}$, and the $28 \mathrm{~d}$ strength of silt soil cement is $1.40 \mathrm{MPa} \sim 3.42 \mathrm{MPa}$.

For muddy soil, when the cement content is less than $360 \mathrm{~kg} / \mathrm{m}^{3}$, the strength of different brands of cement soil is different; when the cement content is more than $360 \mathrm{~kg} / \mathrm{m}^{3}$, the strength of cement soil at $14 \mathrm{~d}$ and $28 \mathrm{~d}$ age and the strength law with the increase of cement content are basically the same; for silt, the strength of cement soil also shows a slight difference under low cement content, which is due to the cement content The formation process of soil strength is the physical and chemical reaction process between cement and soil particles. When the cement content is low, the cement and soil are fully contacted, and the mineral composition and particle fineness of cement play a dominant role in the formation of soil strength.

\section{Conclusion}

According to the indoor mix proportion test results of three brands of cement for four types of marine soft soil with different properties, it can be seen that:

1) The 28d age strength of three brands of PO.42.5 cement soil can reach more than 1.0MPa, which can meet the demand of DCM soft soil reinforcement;

2) Under the same cement content, the cement curing effect of muddy soil and silt is better than that of silt, and the cement curing effect of convective mud is slightly worse; 
3) The strength of flowing mud and silt increases obviously with high cement content (above $400 \mathrm{~kg} / \mathrm{m}^{3}$ ). Because the solidification effect of cement on flowing mud is slightly poor, it is suggested to remove flowing mud layer or pretreat the flowing mud part to meet the engineering economy.

\section{Reference}

1 Compilation of technical documents of cement deep mixing method $[\mathrm{M}]$. CCCC first Navigation Engineering Co., Ltd., 2009

2 Ma Yong. Research on mechanism and engineering application of strength improvement of offshore soft soil cement mixing and consolidation [D]. Dalian University of technology, 2012

3 Liu Zhijun, Tong Xinchun, Xu Zeyuan, Zhou Hongxing, Wang Xin. Indoor sample preparation method and mix proportion test of cement soil [ $\mathrm{J} /$ OL]. Water transport engineering, 2019 (05): 1-5

4 Chen Zhongxue, Li Wenguang, Ren Tao, Liang Peng. Experimental analysis of unconfined compressive strength of cement soil [J]. Highway traffic technology, 2016, 32 (05): 4-8

5 Gong bining, Li Songquan. Study on physical and mechanical properties of soil reinforced by cement deep mixing in soft soil foundation [J]. Journal of Hohai University (NATURAL SCIENCE EDITION), 2000 (02): 101-105

6 Wang Xinhui. Experimental study on strength characteristics of marine soft soil and cement soil [a]. Proceedings of the 9th Conference on soil mechanics and geotechnical engineering of Chinese society of civil engineering [C]. 2003: 4

7 He Yingxi, Li Hanbo, Zhang Kehao, Tang Ming, Xiao Yangchun, Wang Gang. Indoor Proportioning Test and field technology test pile of marine silt reinforced by cement $[\mathrm{J}]$. Water transport engineering, 2018 (07): 35-40+76

8 Ouyang Kelian, Ning baokuan. Study on Influence Factors of cement soil strength [J]. Highway at home and abroad, 2009,29 (04): 189-191

9 Khiem Quang Tran, Tomoaki Satomi, Hiroshi Takahashi. Tensile behaviors of natural fiber and cement reinforced soil subjected to direct tensile test[J]. Journal of Building Engineering, 2019, 24.

10 Code for design of cement soil mix proportion (GJ) T_233-2011) [S]. China Construction Industry Press 